\title{
Karakteristik dan Pola Distribusi Sedimen di Telaga Cebong, Kecamatan Kejajar, Kabupaten Wonosobo
}

\author{
Sediment Characteristics and Distribution Patterns in Cebong Lake, Sub- \\ District of Kejajar, District of Wonosobo
}

\author{
Mira Rosita ${ }^{1}$, Suwarsito $^{2 *}$, Esti Sarjanti ${ }^{3}$ \\ ${ }^{1,2,3}$ Program Studi Pendidikan Geografi, FKIP, \\ Universitas Muhammadiyah Purwokerto \\ *corr-author: suwarsito@ump.ac.id
}

\begin{abstract}
ABSTRAK
Telaga Cebong merupakan salah satu telaga yang terletak di D ataran Tinggi Dieng yang dimanfaatkan masyarakat untuk sumber irigasi lahan pertanian. Telaga Cebong telah mengalami sedimentasi sehingga menyebabkan terjadinya pendangkalan telaga. Penelitian ini bertujuan untuk mengetahui karakteristik dan pola distribusi sedimen di Telaga Cebong, Desa Sembungan, Kecamatan Kejajar, Kabupaten Wonosobo. Penelitian ini menggunakan metode survei. Metode survei dimaksudkan untuk memperoleh data mengenai karakteristik dan pola distribusi sedimen di Telaga Cebong. Sampel penelitian sebanyak 8 titik lokasi, terdiri dari 5 titik lokasi di muara aliran air menuju telaga dan 3 titik lokasi telaga pada kedalaman berbeda. Variabel penelitian meliputi karaktersitik dan pola distribusi sedimen di Telaga Cebong. Data penelitian terdiri dari data sedimen dasar dan sedimen melayang di Telaga Cebong yang diperoleh melalui pengamatan secara langsung di lapangan. Analisis data dilakukan menggunakan deskriptif kualitatif untuk mendeskripsikan karakteristik sedimen. Selain itu, analisis data dilakukan menggunakan analisis keruangan untuk menggambarkan pola distribusi sedimen. Hasil penelitian menunjukkan bahwa karakteristik sedimen di Telaga Cebong didominasi oleh pasir dan debu. Sedimen dasar dan sedimen melayang di Telaga Cebong memiliki ukuran antara 2,0 $-<0,075 \mathrm{~mm}$ (antara jenis pasir dan debu). Konsentrasi sedimen melayang di Telaga Cebong masih termasuk dalam kategori baik pada saat tidak hujan, yaitu $10 \mathrm{mg} / \mathrm{l}$ dan pada saat setelah hujan yaitu antara 12-30 mg/l. Pola distribusi sedimen di Telaga Cebong bersifat heterogen, yaitu menyebar ke seluruh area telaga.
\end{abstract}

Kata kunci: Karakteristik dan Pola distribusi Sedimen, Heterogen, Telaga Cebong

\begin{abstract}
Cebong Lake is one of lake located in the Dieng Plateau which was used by community for agricultural land irrigation. Cebong Lake has undergone sedimentation, causing silting of the lake. The study aims to determine the characteristics and distribution patterns of sediment in Cebong Lake, Sembungan Village, Kejajar District, Wonosobo Regency. The study used a survey method. The survey method was aimed to obtain data on the characteristics and distribution patterns of sediment in Cebong Lake. There were 8 location points of research sample, consist of 5 location points which are the estuaries of the water flow to the lake and 3 location points based on the depth. The variables of the study include the characteristics and distribution patterns of sediments in Cebong Lake. The data of this research consist of bottom sediment and suspended sediments in Cebong
\end{abstract}


Lake which were obtained through direct observation in situ. Data of sediment were analyzed using qualitative descriptive to describe sediment characteristics. In addition, data of sediment were analyzed using spatial analysis to describe sediment distribution patterns. The results of study indicated that the sediment characteristics in Cebong Lake are dominated by sand and dust. The bottom sediments and suspended sediments in Cebong Lake have a size between 2.0 - <0.075 $\mathrm{mm}$ (between types of sand and dust). The suspended sediment concentration in Cebong Lake was categorized in the good category when it did not rain and after the rain, respectively $10 \mathrm{mg} / \mathrm{l}$ and between $12-30 \mathrm{mg} / \mathrm{l}$. The sediment distribution pattern in Cebong Lake was heterogeneous, spreading throughout the lake area.

Keywords: Characteristic and distribution patterns of sediment, Heterogeneous, Cebong Lake

\section{PENDAHULUAN}

Telaga Cebong merupakan salah satu telaga yang terletak di Dataran Tinggi Dieng, Desa Sembungan, Kecamatan Kejajar, Kabupaten Wonosobo. Telaga Cebong terbentuk dari proses aktivitas vulkanik gunung api purba selama jutaan tahun. Telaga Cebong memiliki keunikan tersendiri dibandingkan dengan telaga-telaga lain yang berada di Dataran Tinggi Dieng. Telaga Cebong memiliki morfologi cekungan yang tidak teratur dan cenderung memanjang. Berbeda dengan telaga-telaga lain yang cenderung memiliki morfologi garis tepi danau yang membulat dan teratur (Nurfahmi, 2016).

Penggunaan lahan yang mendominasi di daerah tangkapan air Telaga Cebong adalah untuk lahan pertanian dan permukiman. Lahan pertanian dimanfaatkan untuk tanaman semusim dengan pengolahan lahan secara terus menerus. Menurut Arianti (2012), pengolahan lahan pertanian yang tidak memenuhi kaidah konservasi menyebabkan peningkatan erosi tanah dan sedimentasi. Erosi tanah merupakan salah satu penyebab terjadinya penurunan kualitas air dan sumber masukan sedimen telaga. Hasil erosi tersebut mengalami transportasi dan terkumpul di dalam telaga sehingga menyebabkan pendangkalan.

Pendangkalan yang terjadi di Telaga Cebong mengakibatkan penurunan daya dukung telaga yang airnya dimanfaatkan oleh masyarakat untuk sumber irigasi lahan pertanian pada musim kemarau. Pendangkalan tersebut ditandai dengan menyempitnya luas Telaga Cebong dari 12 ha menjadi 8 ha saja atau hanya 8,1\% dari seluruh luas daerah tangkapan airnya yaitu seluas 98,58 Ha (Sudarmadji et. al, 2015). Kedalaman rata-rata telaga adalah 2,25 meter dan kedalaman maksimumnya adalah 4,05 meter. Hal ini menyebabkan terjadinya ketidakseimbangan antara ketersediaan air telaga terhadap kebutuhan irigasi pertanian (Sari dan Sudarmadji, 2017).

Penelitian mengenai karakteristik dan pola distribusi sedimen telah dilakukan oleh beberapa peneliti. Hambali dan Apriyanti (2016) melakukan penelitian tentang karakteristik sedimen dan laju sedimentasi Sungai Daeng, Kabupaten Bangka Barat. Wisha et al. (2017) juga telah melakukan penelitian mengenai pola sebaran sedimen dasar berdasarkan karakteristik morfologi dan hidro-oseanografi menggunakan model interpolasi dan simulasi numerik di perairan utara Pulau Simeuluecut. Lebih lanjut, Putra dan Nugroho (2017) juga telah melakukan penelitian tentang distribusi sedimen permukaan dasar laut perairan Sumba, Nusa Tenggara Timur. Namun, penelitian mengenai karakteristik dan pola distribusi sedimen di perairan menggenang terutama di telaga belum banyak dilakukan. Oleh karena itu, perlu dilakukan penelitian tentang karakteristik dan pola distribusi sedimen di telaga. Tujuan dari penelitian ini adalah untuk mengetahui karakteristik dan pola 
distribusi sedimen di Telaga Cebong, Desa Sembungan, Kecamatan Kejajar, Kabupaten Wonosobo.

\section{METODE}

Penelitian ini menggunakan metode survey. Metode survei digunakan untuk memperoleh data mengenai karakteristik dan pola distribusi sedimen di Telaga Cebong Desa Sembungan, Kecamatan Kejajar, Kabupaten Wonosobo. Penelitian ini dilaksanakan pada Bulan April - Juli tahun 2019.

Alat yang digunakan untuk penelitian adalah:

1. GPS (Global Positioning System) digunakan untuk menentukan titik koordinat lokasi penelitian.

2. Pipa paralon untuk mengambil sampel sedimen di dasar telaga.

3. Kertas saring Whatman ukuran $150 \mathrm{~mm}$ digunakan untuk menyaring sedimen.

4. Oven digunakan untuk memanaskan dan mengeringkan sedimen.

5. Timbangan analitik digunakan untuk menimbang berat kertas saring dan sedimen.

6. Saringan 7 sieve untuk menyaring hasil sedimen dasar.

Bahan yang digunakan untuk penelitian adalah:

1. Peta RBI Kabupaten Wonosobo lembar $1408-442$ skala $1: 25.000$.

2. Citra Landsat Google Earth tahun 2018.

3. Peta titik lokasi penelitian skala 1:7000.

Variabel penelitian terdiri dari 2 variabel, yaitu karakteristik dan pola distribusi sedimen di Telaga Cebong. Data penelitian ini berupa data primer, yaitu data sedimen dasar dan sedimen melayang di Telaga Cebong yang diperoleh melalui pengamatan secara langsung di lapangan. Sampel penelitian terdiri dari 8 titik lokasi penelitian, terdiri dari 5 titik lokasi, yaitu muara aliran air menuju telaga dan 3 titik lokasi berdasarkan kedalaman telaga.

Teknik pengumpulan data primer dilakukan secara in situ dengan cara mengambil data langsung di lapangan saat tidak hujan dan saat setelah hujan. Sampel yang diambil dari lokasi penelitian adalah sampel sedimen dasar dan sedimen melayang. Sampel sedimen dasar diambil pada saat tidak hujan dan sampel sedimen melayang diambil saat setelah hujan dan tidak hujan sebanyak 1 liter. Titik pengambilan sampel ditentukan berdasarkan sumber aliran dari daerah tangkapan air telaga dan kedalaman telaga. Selanjutnya sedimen tersebut dilakukan uji laboratorium guna mengetahui ukuran butiran, gradasi, keseragaman, dan konsentrasi sedimen melayangnya.

Sampel sedimen dasar diambil pada 5 lokasi titik sampel dan 3 titik sampel berdasarkan kedalaman telaga. Sampel sedimen dasar hanya diambil satu kali saat tidak hujan. Sampel yang telah diperoleh selanjutnya dilakukan uji laboratorium di Laboratorium Mekanika Tanah Fakultas Teknik dan Sains Universitas Muhammadiyah Purwokerto. Sampel sedimen dikeringkan dalam suhu $105^{\circ} \mathrm{C}$ selama 24 jam, yang selanjutnya dilakukan pengayakan dengan menggunakan saringan standar Amerika. Dari hasil pengayakan dapat diketahui persentase lolos dan berat yang tertahan di setiap nomer ayakan, sehingga dapat diketahui klasifikasi butiran yang terkandung dalam setiap sampel. Klasifikasi jenis butiran sedimen ditentukan berdasarkan klasifikasi menurut Asdak (2010).

Pengambilan sampel sedimen melayang dilakukan 2 kali yaitu saat tidak hujan dan saat setelah hujan dengan masing-masing sampel adalah 1 liter pada kedalaman 1 meter. Selanjutnya sampel tersebut dilakukan uji laboratorium sehingga menghasilkan nilai konsentrasi sedimen melayang. Nilai dari konsentrasi sedimen kemudian dikategorikan 
sesuai dengan standar kualitas lingkungan hidup menurut Keputusan Menteri KLH No.2 tahun 1988 tentang Penetapan Baku Mutu Lingkungan. Teknik pengolahan data penelitian dilakukan terhadap data karakteristik dan pola distribusi sedimen.

\section{Karakteristik Sedimen}

Karakteristik sedimen dasar yang dikaji dalam penelitian ini adalah ukuran butiran, gradasi dan keseragaman. Distribusi ukuran butiran sedimen dilakukan dengan penyaringan. Sampel sedimen disaring menggunakan satu unit saringan standar untuk pengujian sedimen. Berat sedimen yang ditinggal pada masing-masing saringan ditimbang dan dihitung persentase kumulatif pada setiap saringan (Hadiyatmo, 2010).

Hasil dari penyaringan tersebut menunjukkan jenis butiran yang terkandung dalam setiap sampel. Jenis butiran dapat diketahui dari persentase sampel yang lolos maupun yang tertahan dalam saringan. Jenis butiran yang dapat diketahui dari penyaringan sedimen dasar ini menurut Wenworth (1922) yaitu:
1. Kerikil Kasar
: Lolos saringan 3" dan tertahan di 3/4",
2. Kerikil Sangat Halus
: Lolos saringan 3/4" dan tertahan di No.8
3. Pasir Sangat Kasar
: Lolos saringan No.8 dan tertahan di No. 16
4. Pasir Kasar
: Lolos saringan No. 16 dan tertahan di No. 20
5. Pasir Sedang
: Lolos saringan No. 20 dan tertahan di No. 60
6. Pasir Sangat Halus
7. Debu
: Lolos saringan No. 60 dan tertahan di No. 200
: Lolos saringan No. 200

Analisis data penelitian dilakukan terhadap data karakteristik dan pola distribusi sedimen.

\section{Analisis Karakteristik Sedimen}

1. Sedimen Dasar

a. Jenis dan Ukuran Butir Sedimen

Hasil pengayakan menggunakan metode 7 sieve disajikan dalam bentuk grafik distribusi ukuran butiran (Grain Size) dalam skala logaritmic dan persentase ukuran butiran yang lolos ayakan digambarkan dalam skala hitung biasa. Batasan ukuran butiran menggunakan klasifikasi menurut Wentworth (1922). Rentang batas ukuran dan klasifikasi butiran disajikan pada Tabel 1.

Tabel 1. Ukuran dan Klasifikasi Butiran Sedimen

\begin{tabular}{cc}
\hline $\begin{array}{c}\text { Ukuran Butiran } \\
(\mathrm{mm})\end{array}$ & Klasifikasi \\
\hline$>64$ & Batu \\
$32-64$ & Kerikil sangat kasar \\
$16-32$ & Kerikil kasar \\
$8-16$ & Kerikil sedang \\
$4-8$ & Kerikil halus \\
$2-4$ & Kerikil sangat halus \\
$1-2$ & Pasir sangat kasar \\
$0.5-1$ & Pasir kasar \\
$0.25-0.5$ & Pasir sedang \\
$0.125-0.25$ & Pasir halus \\
$0.062-0.125$ & Pasir sangat halus \\
$0.031-0.062$ & Debu kasar \\
$0.016-0.031$ & Debu sedang \\
$0.008-0.016$ & Debu halus \\
$0.004-0.008$ & Debu sangat halus \\
$<0.004$ & Lempung \\
\hline
\end{tabular}


b. Gradasi dan Keseragaman

Hasil pengukuran butir partikel yang telah diperoleh selanjutnya dianalisis tingkat gradasi dan keseragamannya. Hal ini dilakukan untuk mengetahui tingkat gradasi dan keseragaman butiran sedimen. Nilai koefisien gradasi dan keseragaman butiran dihitung menggunakan rumus berikut (Hadiyatmo, 2010):

1) Koefisien Gradasi

$$
\mathrm{Cc}=\begin{gathered}
D 30^{2} \\
D \overline{10} x^{-} D \overline{60}
\end{gathered}
$$

$\mathrm{Cc}=$ koefisien gradasi

D30 = diameter yang bersesuaian dengan $30 \%$ lolos ayakan.

D10 = diameter yang bersesuaian dengan $10 \%$ lolos ayakan.

D60 = diameter yang bersesuaian dengan $60 \%$ lolos ayakan .

2) Koefisien Keseragaman

\section{Sedimen Melayang}

$\mathrm{Cu}=$ koefisien keseragaman

D60 = diameter yang bersesuaian dengan $60 \%$ lolos ayakan.

D10 = diameter yang bersesuaian dengan $10 \%$ lolos ayakan.

Analisis data muatan sedimen melayang dilakukan dengan cara matching data sedimen melayang dengan kategori standar konsentrasi sedimen melayang berdasarkan Kep. Men. KLH No.2/1988 tentang standar kualitas lingkungan, seperti ditunjukkan pada Tabel 2.

Tabel 2. Nilai Standar Konsentrasi Sedimen Melayang

\begin{tabular}{cc}
\hline Konsentrasi Sedimen Melayang $(\mathrm{mg} / \mathrm{l})$ & Kategori \\
\hline $0-100$ & Baik \\
$100-$ & Sedang \\
250 & \\
$250-$ & Jelek \\
500 & \\
$>500$ & Sangat Jelek \\
\hline
\end{tabular}

Analisis data pola distribusi sedimen dilakukan menggunakan analisis keruangan. Distribusi ukuran butiran dapat dilihat dari persebaran jenis dan ukuran butiran.

\section{HASIL DAN PEMBAHASAN}

\section{Karakteristik Sedimen}

\section{Sedimen Dasar}

Hasil analisis butiran menunjukkan bahwa sedimen dasar di Telaga Cebong terdiri dari jenis kerikil sangat halus hingga debu. Pada sampel 1 menunjukkan bahwa terdapat 2 $\%$ kerikil sangat halus, 7,09\% pasir sangat kasar, 3,64\% pasir kasar, 20,91\% pasir sedang, $39,46 \%$ pasir sangat halus dan 26,91\% debu. Sampel 2 menunjukkan 7,52\% kerikil sangat halus, 10,40\% pasir sangat kasar, 3,44\% pasir kasar, 22,88\% pasir sedang, 32,48 \% pasir sangat halus dan $23,28 \%$ debu. Sampel 3 terdapat 1,67 \% pasir sangat kasar, $1 \%$ pasir kasar, 
6,66\% pasir sedang, 23,66\% pasir sangat halus dan 67\% debu. Sampel 4 menunjukkan $6,67 \%$ pasir sangat kasar, $10 \%$ pasir kasar, $15,56 \%$ pasir sedang, $22,22 \%$ pasir sangat halus, dan $45,56 \%$ debu. Sampel 5 menunjukkan $0,50 \%$ kerikil sangat halus, $2 \%$ pasir sangat kasar, 1,25\% pasir kasar, $10 \%$ pasir sedang, $34 \%$ pasir sangat halus, dan 52,25\% debu.

Table 3. Hasil Jenis Butiran Sedimen Dasar Menurut Wenworth (1922)

\begin{tabular}{ccccccc}
\hline Nomer & \multicolumn{6}{c}{ Kandungan Sedimen } \\
\cline { 2 - 7 } Sampel & $\begin{array}{c}\text { Kerikil } \\
\text { Sangat } \\
\text { Halus } \\
(\%)\end{array}$ & $\begin{array}{c}\text { Pasir } \\
\text { Sangat } \\
\text { Kasar (\%) }\end{array}$ & $\begin{array}{l}\text { Pasir } \\
\text { Kasar (\%) }\end{array}$ & $\begin{array}{l}\text { Pasir } \\
\text { Sedang (\%) }\end{array}$ & $\begin{array}{l}\text { Pasir } \\
\text { Sangat } \\
\text { Halus (\%) }\end{array}$ & $\begin{array}{c}\text { Debu } \\
(\%)\end{array}$ \\
\hline 1 & 2 & 7,09 & 3,64 & 20,91 & 39,46 & 26,91 \\
2 & 7,52 & 10,40 & 3,44 & 22,88 & 32,48 & 23,28 \\
3 & 0 & 1,67 & 1 & 6,66 & 23,66 & 67 \\
4 & 0 & 6,67 & 10 & 15,56 & 22,22 & 45,56 \\
5 & 0,50 & 2 & 1,25 & 10 & 34 & 52,25 \\
\hline
\end{tabular}

Sumber : Data Primer (2019)

Hasil analisis jenis butiran berdasarkan kedalamannya, pada kedalaman 4 meter menunjukkan 2,22\% kerikil sangat halus, 6,67\% pasir sangat kasar, 2,78\% pasir kasar, $13,89 \%$ pasir sedang, 15,56\% pasir sangat halus, dan 58,89\% debu. Pada kedalaman 2 meter terdapat 5,29\% kerikil sangat halus, 4,21\% pasir sangat kasar, 3,53\% pasir kasar, $21,77 \%$ pasir sedang, $27,05 \%$ pasir sangat halus, dan 38,24\% debu. Pada kedalaman 1 meter terdapat $18,10 \%$ kerikil sangat halus, $21,90 \%$ pasir sangat kasar, 7,62\% pasir kasar, $23,34 \%$ pasir sedang, $16,03 \%$ sangat halus, dan $13,02 \%$ debu.

Tabel 4. Hasil Jenis Butiran Sedimen Berdasarkan Kedalaman

\begin{tabular}{|c|c|c|c|c|c|c|c|}
\hline \multirow[t]{2}{*}{$\begin{array}{l}\text { Nomer } \\
\text { Sampel }\end{array}$} & \multirow[t]{2}{*}{$\begin{array}{c}\text { Kedala } \\
\operatorname{man}(\mathrm{m})\end{array}$} & \multicolumn{6}{|c|}{$\begin{array}{c}\text { Kandungan } \\
\text { Sedimen }\end{array}$} \\
\hline & & $\begin{array}{c}\text { Kerikil } \\
\text { Sangat } \\
\text { Halus } \\
(\%)\end{array}$ & $\begin{array}{l}\text { Pasir } \\
\text { Sangat } \\
\text { Kasar }(\%)\end{array}$ & $\begin{array}{l}\text { Pasir } \\
\text { Kasar (\%) }\end{array}$ & $\begin{array}{l}\text { Pasir Sedang } \\
(\%)\end{array}$ & $\begin{array}{l}\text { Pasir Sangat } \\
\text { Halus }(\%)\end{array}$ & $\begin{array}{l}\text { Debu } \\
(\%)\end{array}$ \\
\hline 6 & 4 & 2,22 & 6,67 & 2,78 & 13,89 & 15,56 & 58,89 \\
\hline 7 & 2 & 5,29 & 4,21 & 3,53 & 21,77 & 27,05 & 38,24 \\
\hline 8 & 1 & 18,10 & 21,90 & 7,62 & 23,34 & 16,03 & 13,02 \\
\hline
\end{tabular}

Sumber : Data Primer (2019)

Analisis gradasi dan keseragaman sampel sedimen dasar di telaga menunjukkan bahwa sebagian besar memiliki tingkat koefisien gradasi $(\mathrm{Cc})$ buruk karena nilainya $<1$. Namun pada kedalaman 1 meter memiliki tingkat koefisien gradasi $(\mathrm{Cc})$ yang baik. Tingkat koefisien keseragaman $(\mathrm{Cu})$ sedimen dasar termasuk kategori baik karena nilainya $>4$. Namun pada sampel sedimen 2 dan 5 termasuk dalam kategori buruk. Hasil analisis gradasi dan keseragaman sedimen dasar dapat dilihat pada Tabel 3. 
Tabel 5. Hasil Koefisien Gradasi dan Keseragaman Sedimen Dasar

\begin{tabular}{lcccc}
\hline \multicolumn{1}{c}{ Keterangan } & $\begin{array}{c}\text { Koefisien } \\
\text { Gradasi (Cc) }\end{array}$ & $\begin{array}{c}\text { Kategori } \\
\text { Gradasi }\end{array}$ & $\begin{array}{c}\text { Koefisien } \\
\text { Keseragaman } \\
(\mathrm{Cu})\end{array}$ & $\begin{array}{c}\text { Kategori } \\
\text { Keseragaman }\end{array}$ \\
\hline Sampel 1 & 0,55 & Buruk & 8,8 & Baik \\
Sampel 2 & 0,03 & Buruk & 3,5 & Buruk \\
Sampel 3 & 0,05 & Buruk & 4,61 & Baik \\
Sampel 4 & 0,23 & Buruk & 14 & Baik \\
Sampel 5 & 0,49 & Buruk & 4 & Buruk \\
Sampel 6 (4 Meter) & 0,22 & Buruk & 10 & Baik \\
Sampel 7 (2 Meter) & 0,19 & Buruk & 7,2 & Baik \\
Sampel 8 (1 Meter) & 2,44 & Baik & 16,85 & Baik \\
\hline
\end{tabular}

Sumber : Data Primer (2019)

Berdasarkan hasil uji laboratorium, gradasi dan keseragaman pada setiap sampel sedimen menunjukkan bahwa karakteristik sedimen yang terkandung pada setiap sampel terdiri dari jenis kerikil sangat halus, pasir sangat kasar, pasir kasar, pasir sedang, pasir sangat halus, dan debu. Pada sampel 1 menunjukkan bahwa sampel didominasi oleh pasir sangat halus yaitu 39,46\% dari total berat sampel. Hal ini disebabkan oleh beberapa faktor yaitu penggunaan lahan dan kemiringan lereng pada wilayah yang menjadi sumber sedimen pada lokasi sampel 1. Wilayah yang menjadi sumber sedimen pada sampel 1 terdiri dari 4 jenis penggunaan lahan yaitu tegalan, belukar, hutan dan lahan kosong. Tegalan menyuplai paling banyak sumber sedimen. Namun, hasil erosi yang terangkut sebagian besar berhenti di lahan kosong yang berada tidak jauh dari telaga, sehingga sisa energi kinetik air hujan hanya membawa partikel tanah yang berbutir lebih halus masuk ke dalam telaga.

Pada sampel 2 menunjukkan bahwa sampel juga didominasi oleh jenis pasir halus yaitu 32,48\%. Penggunaan lahan pada sumber sedimen sampel 2 terdiri dari 2 jenis penggunaan lahan yaitu tegalan dan permukiman. Dari penggunaan lahan tersebut dapat dilihat bahwa tegalan menjadi pemasok utama sedimen pada sampel 2, permukiman tidak memiliki banyak andil dikarenakan pada jenis penggunaan lahan ini terjadi erosi. Namun aktivitas-aktivitas masyarakatlah yang cenderung mengakibatkan sedimen masuk kedalam telaga seperti membuang bekas galian sumur atau yang lain di daerah sekitar telaga.

Pada sampel 3,4 dan 5 menunjukkan bahwa penggunaan lahan tegalan lebih banyak menghasilkan jenis sedimen debu. Hal ini dikarenakan oleh pengolahan lahan yang terjadi di tegalan tersebut yang mengakibatkan tanah yang berbutir halus banyak terangkut ke dalam telaga.

\section{Sedimen Melayang}

Data konsentrasi sedimen melayang pada saat tidak hujan di Telaga Cebong sebesar $10 \mathrm{mg} / \mathrm{l}$. Konsentrasi sedimen melayang pada saat setelah hujan menunjukkan nilai sebagai berikut: sampel 1 sebesar $16 \mathrm{mg} / \mathrm{l}$, sampel 2 sebesar $24 \mathrm{mg} / \mathrm{l}$, sampel 3 sebesar 12 $\mathrm{mg} / \mathrm{l}$, sampel 4 sebesar $20 \mathrm{mg} / \mathrm{l}$ dan sampel 5 sebesar $30 \mathrm{mg} / \mathrm{l}$. Hasil pengolahan data tersebut apabila disesuaikan dengan kategori menurut standar kualitas lingkungan hidup Kep. Men. KLH No.2/1988 termasuk dalam kategori baik karena masih dalam rentang nilai antara $0-100 \mathrm{mg} / \mathrm{l}$. 
Tabel 6. Konsentrasi Sedimen Melayang Saat Tidak Hujan

\begin{tabular}{|c|c|c|c|c|c|}
\hline \multirow{2}{*}{\multicolumn{2}{|c|}{ Lokasi }} & \multicolumn{4}{|c|}{ Konsentrasi Sedimen } \\
\hline & & \multirow{2}{*}{$\begin{array}{c}\text { Berat } \\
\text { Kertas } \\
\text { Awal (g) }\end{array}$} & \multirow{2}{*}{$\begin{array}{c}\text { Berat } \\
\text { Kertas } \\
\text { Konstan } \\
(\mathrm{g})\end{array}$} & \multirow{2}{*}{$\begin{array}{c}\text { Berat } \\
\text { Sedimen } \\
\text { Kering (g) }\end{array}$} & \multirow{2}{*}{ Hasil mg/ } \\
\hline Lintang & Bujur & & & & \\
\hline $7^{\circ} 14^{\prime} 11.22^{\prime \prime S}$ & $\begin{array}{c}109^{\circ} 55^{\prime} 16.11 " \\
\mathrm{~T}\end{array}$ & 0,52 & 0,50 & 0,55 & 10 \\
\hline $7^{\circ} 14^{\prime} 6.53 " \mathrm{~S}$ & $109^{\circ} 55^{\prime} 6.28^{\prime \prime T}$ & 0,52 & 0,50 & 0,55 & 10 \\
\hline $7^{\circ} 14^{\prime} 12.83 " \mathrm{~S}$ & $109^{\circ} 55^{\prime} 9.52 " \mathrm{~T}$ & 0,52 & 0,50 & 0,55 & 10 \\
\hline $7^{\circ} 14^{\prime} 15.32 " S$ & $\begin{array}{c}109^{\circ} 55^{\prime} 15.25^{\prime \prime} \\
\mathrm{T}\end{array}$ & 0,52 & 0,50 & 0,55 & 10 \\
\hline $7^{\circ} 14^{\prime} 14.54 " \mathrm{~S}$ & $\begin{array}{c}109^{\circ} 55^{\prime} 17.30^{\prime \prime} \\
\mathrm{T}\end{array}$ & 0,52 & 0,50 & 0,55 & 10 \\
\hline
\end{tabular}

Sumber : Data Primer (2019)

Tabel 7. Konsentrasi Sedimen Melayang Saat Setelah Hujan

\begin{tabular}{|c|c|c|c|c|c|}
\hline \multirow{2}{*}{\multicolumn{2}{|c|}{ Lokasi }} & \multicolumn{4}{|c|}{ Konsentrasi Sedimen } \\
\hline & & \multirow{2}{*}{$\begin{array}{c}\text { Berat } \\
\text { Kertas } \\
\text { Awal } \\
\text { (g) }\end{array}$} & \multirow{2}{*}{$\begin{array}{c}\text { Berat } \\
\text { Kertas } \\
\text { Konstan } \\
(\mathrm{g})\end{array}$} & \multirow{2}{*}{$\begin{array}{c}\text { Berat } \\
\text { Sedimen } \\
\text { Kering } \\
(\mathrm{g})\end{array}$} & \multirow[t]{2}{*}{ Hasil Mg/l } \\
\hline Lintang & Bujur & & & & \\
\hline $7^{\circ} 14^{\prime} 11.22^{\prime \prime S}$ & $109^{\circ} 55^{\prime} 16.11^{\prime \prime T}$ & 0,52 & 0,50 & 0,58 & 16 \\
\hline $7^{\circ} 14^{\prime} 6.53 " \mathrm{~S}$ & $109^{\circ} 55^{\prime} 6.28^{\prime \prime T}$ & 0,52 & 0,50 & 0,62 & 24 \\
\hline $7^{\circ} 14^{\prime} 12.83 " \mathrm{~S}$ & $109^{\circ} 55^{\prime} 9.52^{\prime \prime T}$ & 0,52 & 0,50 & 0,56 & 12 \\
\hline $7^{\circ} 14^{\prime} 15.32 " \mathrm{~S}$ & $109^{\circ} 55^{\prime} 15.25^{\prime \prime T}$ & 0,52 & 0,50 & 0,60 & 20 \\
\hline $7^{\circ} 14^{\prime} 14.54 " \mathrm{~S}$ & $109^{\circ} 55^{\prime} 17.30^{\prime \prime T}$ & 0,52 & 0,50 & 0,65 & 30 \\
\hline
\end{tabular}

Sumber : Data Primer (2019)

Berdasarkan hasil uji sedimen melayang pada sampel-sampel yang telah diambil dari Telaga Cebong menunjukkan bahwa konsentrasi sedimen masih dalam kategori baik, yaitu masih dalam rentang angka $0-100 \mathrm{mg} / \mathrm{l}$. Hal ini dipengaruhi oleh kondisi lingkungan. Nilai konsentrasi sedimen melayang pada saat tidak hujan cenderung lebih rendah dari pada saat setelah hujan. Pada setiap sampel menunjukkan adanya peningkatan konsentrasi sedimen saat tidak hujan dan setelah hujan. Peningkatan konsentrasi sedimen tidak begitu signifikan karena pada saat pengambilan sampel, intensitas hujannya kecil dan hanya terjadi selama 20 menit saja yaitu pada pukul 13.20-13.40. Besar kemungkinannya apabila intensitas hujan besar dengan kurun waktu yang lama akan menghasilkan konsentrasi sedimen yang lebih banyak.

\section{Pola Distribusi Sedimen}

Berdasarkan hasil analisis butiran dan analisis keruangan, pola distribusi sedimen dasar menunjukkan jenis butiran pasir dan debu lebih dominan di Telaga Cebong. Pola distribusi sedimen dasar bersifat heterogen, menyebar ke seluruh area Telaga Cebong. Sebaran sedimen menunjukkan bahwa sebaran kerikil halus hanya terdapat di 3 lokasi yaitu pada sampel 1, 3, dan 5 saja. Sedangkan sedimen pasir dan debu terdapat di seluruh lokasi pengambilan sampel sedimen. Sebaran kerikil halus kurang lebih $4 \%$ dari seluruh luas telaga. Sebaran pasir mencakup sekitar $61 \%$ dari seluruh luas telaga, terdiri dari $7 \%$ pasir sangat kasar, 3\% pasir kasar, $18 \%$ pasir sedang, dan 33\% pasir sangat halus. Sedimen jenis debu mencakup sekitar 35\% dari seluruh luas telaga. Berdasarkan kedalaman telaga menunjukkan bahwa jenis kerikil halus lebih banyak berada di kedalaman 1 meter, sedangkan jenis pasir lebih mendominasi pada kedalaman 2 meter dan jenis debu lebih 
mendominasi pada kedalaman 4 meter. Peta pola distribusi sedimen dasar disajikan pada Gambar 1 .

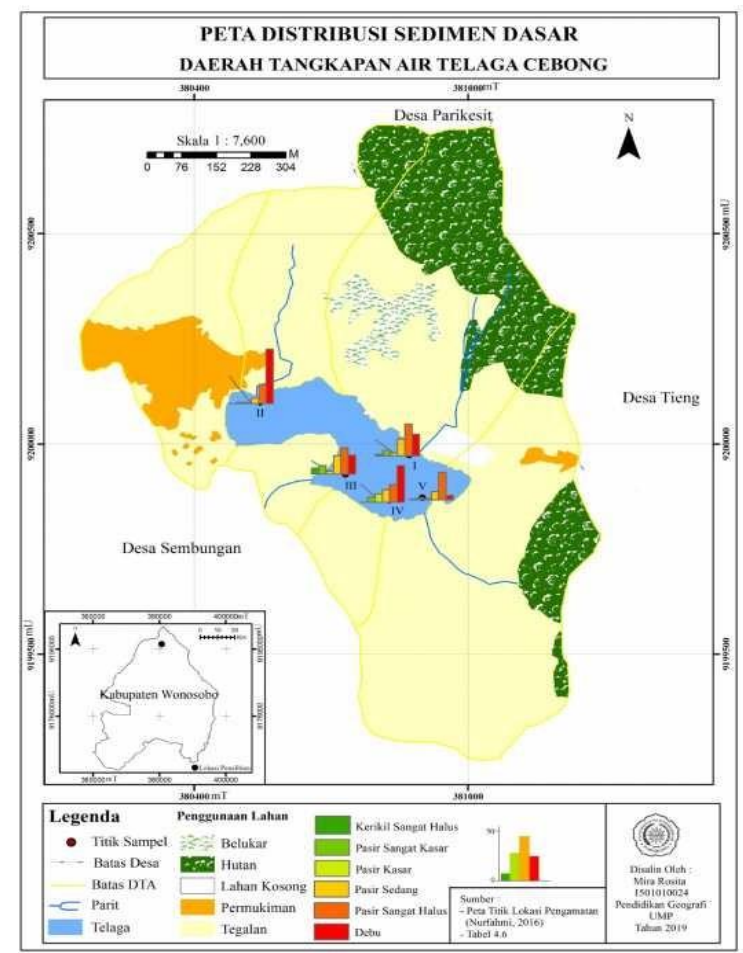

Gambar 1. Peta Pola Distribusi Sedimen Dasar

Pola distribusi sedimen melayang pada Telaga Cebong dari 5 titik pengambilan sampel saat tidak hujan menunjukkan kategori baik yaitu $10 \mathrm{mg} / \mathrm{l}$, sedangkan saat setelah hujan adalah antara 12-30 mg/l. Berdasarkan hasil analisis keruangan menunjukkan bahwa sebaran sedimen melayang di Telaga Cebong cenderung sama di seluruh telaga. Pola distribusi sedimen melayang juga bersifat heterogen, yaitu menyebar ke seluruh area Telaga Cebong. Peta pola distribusi sedimen melayang dapat dilihat pada Gambar 2. 


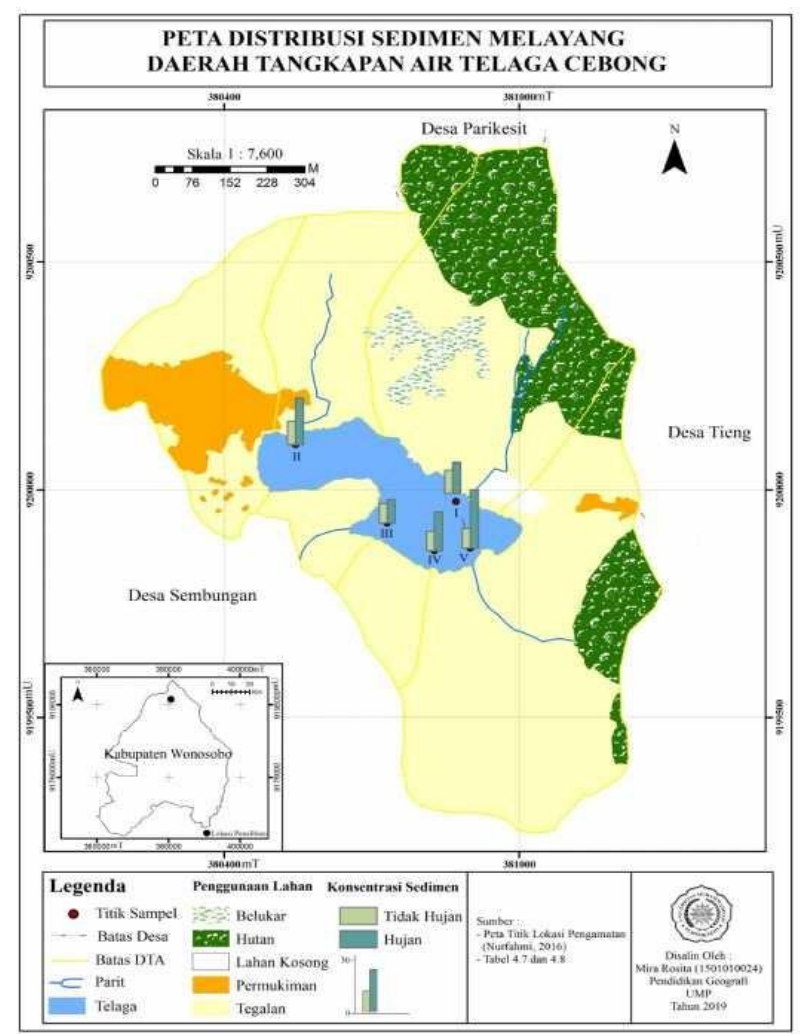

Gambar 2. Peta Pola Distribusi Sedimen Melayang

Hasil penelitian ini berbanding terbalik dengan penelitian yang dilakukan oleh Anshar (2014) di Sungai Pute, Rammang-rammang Kawasan Karst Maros yang menunjukkan bahwa sedimen di sungai tersebut termasuk kategori tinggi/jelek yaitu lebih dari $100 \mathrm{mg} / \mathrm{l}$. Hal ini dikarenakan sedimentasi di sungai terjadi dari hulu ke hilir dengan kondisi daerah tangkapan yang luas dan jenis penggunaan lahan yang lebih kompleks. Berbeda dengan sedimen di Telaga Cebong ini dikarenakan sumber sedimen hanya meyuplai saat hujan saja karena tidak ada aliran air yang bersifat konstan ke dalam telaga.

\section{KESIMPULAN}

Karakteristik sedimen di Telaga Cebong didominasi oleh pasir dan debu. Sedimen dasar dan sedimen melayang di Telaga Cebong memiliki ukuran antara 2,0 $-<0,075 \mathrm{~mm}$ atau antara jenis pasir dan debu. Konsentrasi sedimen melayang di Telaga Cebong masih termasuk dalam kategori baik pada saat tidak hujan, yaitu $10 \mathrm{mg} / \mathrm{l}$ dan pada saat setelah hujan yaitu antara $12-30 \mathrm{mg} / \mathrm{l}$. Pola distribusi sedimen di Telaga Cebong bersifat heterogen, yaitu menyebar ke seluruh area telaga.

Disarankan untuk melakukan penelitian lanjutan tentang pengaruh penggunaan lahan di daerah tangkapan hujan Desa Sembungan terhadap pola distribusi sedimen di Telaga Cebong pada saat musim kemarau dan musim hujan.

\section{DAFTAR PUSTAKA}

Anshar, N.A. 2014. Studi Analisis Sedimentasi di Sungai Pute Rammang-Rammang Kawasan Karst Maros. Jurnal Sains dan Pendidikan Fisika, Jilid 10, Nomor 3: 301-307. 
Asdak, C. 2010. Hidrologi dan Pengelolaan Daerah Aliran Sungai. Yogyakarta: Gadjah Mada University Press.

Arianti. 2012. Dampak pengelolaan lahan Pertanian terhadap hasil Sedimen di Daerah Aliran Sungai Galeh Kabupaten Semarang. Jurnal Manusia dan Lingkungan, Volume 19 (3): 238-246.

Hambali, R. dan Y. Apriyanti. 2016. Studi Karakteristik Sedimen dan Laju Sedimentasi Sungai Daeng - Kabupaten Bangka Barat. Jurnal Fropil, Volume 4 (2): 165 -174.

Hardiyatmo, H.C.2010. Mekanika Tanah 1. 398 hal. Yogyakarta: Gama Press

Keputusan Menteri KLH No. 2 Tahun 1988. Tentang Penetapan Baku Mutu Lingkungan. http://komara.weebly.com/peraturan-lingkungan/keputusan-menteri-negaralingkungan-hidup-no-02-tahun-1988-tentang-pedoman-penetapan-baku-mutulingkungan-obsolete-untuk-bab-iv-dan-lampirannya. Tanggal Akses 22 april 2019. Pukul 20.20.

Nurfahmi, P. 2016. Studi Karakteristik Sedimen Dasar dan Tanah Pertanian di Daerah Tangkapan Air Telaga Cebong Kecamatan Kejajar Kabupaten Wonosobo. Skripsi. Yogyakarta : Fakultas Geografi Universitas Gajah Mada.

Putra, P.S dan S.H. Nugroho. 2017. Distribusi Sedimen Permukaan Dasar Laut Perairan Sumba, Nusa Tenggara Timur. Oseanologi dan Limnologi di Indonesia, Volume 2 (3): 49-63.

Sari, R.P. dan Sudarmadji. 2017. Daya Dukung Telaga Cebong untuk Pemenuhan Kebutuhan Air Irigasi Pertanian Kentang di Desa Sembungan Kecamatan Kejajar Kabupaten Wonosobo. Jurnal Bumi Indonesia. Volume 6 (1): 1 - 10.

Sudarmadji, H. Supriyono, dan S. Lestari. 2015. Danau-danau Volkanik di Dataran Tinggi Dieng: Pemanfaatan dan Masalah yang Dihadapi. Jurnal Teknosains, Volume 5 (1): $36-48$.

Wentworth, C.K. 1922. A scale of grade and class term for clastic sediment. J. Geology, 30:337-392.

Wisha, U.J. W.A. Gemilang, G.A.Rahmawan, dan G. Kusumah. 2017. Pola Sebaran Sedimen Dasar Berdasarkan Karakteristik Morfologi dan Hidro-Oseanografi Menggunakan Model Interpolasi dan Simulasi Numerik di Perairan Utara Pulau Simeuluecut. Jurnal Kelautan, Volume 10 (1): 29 -40. 